\title{
Docking Study to Predict the Efficacy of Phosphatidylinositol 3-Kinase $\alpha$ Inhibitors
}

\author{
Mahmoud A. Chawsheen ${ }^{1}$, Hazem A. Al-Bustany ${ }^{2}$ \\ ${ }^{1}$ Department of General Sciences, Faculty of Education, Soran University, \\ Erbil, Kurdistan Region - F.R. Iraq \\ ${ }^{2}$ Department of Basic Science, College of Medicine, Hawler Medical University, \\ Erbil, Kurdistan Region - F.R. Iraq
}

\begin{abstract}
The phosphatidylinositol 3-kinase (PI3K) family comprises lipid kinases that cross-link signals between living cells and their surroundings. PI3Ks are classified into several groups and isoforms with specific characteristics and functions. Genes encoding PI3Ks are mutated in several types of cancer, and their isoforms have varying capacity in promoting cell signaling and cancer progression. Many compounds have been introduced as PI3Ka inhibitors, but not all of them have the same inhibitory effects. For successful PI3K-related biomedical experiments, it is vital to select the most specific and potent compounds with the highest inhibitory effects for targeting this kinase. In this study, we investigate 28 well-recognized PI3Ka inhibitors through predicting their specificity and potency using the docking software AutoDock Vina. Our data showed that PF 05212384 had the highest docking score $(-9.2 \mathrm{kcal} / \mathrm{mol})$, and 3-methyladenine had the lowest docking score $(-4.8 \mathrm{kcal} / \mathrm{mol})$. Our data also showed different types of interactions and bonds formed between the inhibitors and protein residues. In conclusion, PF 05212384 and AZD 6482 compounds are the best candidates for targeting PI3Ka. In addition to hydrophobic interactions in the PI3K $\alpha$ binding pocket, the formation of hydrogen bonds between these inhibitors and binding pocket residues was confirmed.
\end{abstract}

Index Terms-AutoDock Vina, Cancer cell, Cell signaling, Docking, Phosphatidylinositol 3-kinase, Phosphatidylinositol 3-kinase $\alpha$.

\section{INTRODUCTION}

The phosphatidylinositol 3-kinase (PI3K) family is a group of lipid kinases that interlink signals between living cells and their surroundings. These kinases affect downstream targets that modulate signaling pathways involved in cell proliferation, growth, survival, vesicle transport, cytoskeletal rearrangement, motility, and metabolism (Vivanco and Sawyers, 2002; Luo, et al., 2003; Engelman, et al., 2006; Liu, et al., 2009; Hancock, 2010). PI3Ks are activated

ARO-The Scientific Journal of Koya University Volume VII, No.2 (2019), Article ID: ARO.10565, 6 pages DOI: $10.14500 /$ aro. 10565

Received 10 September 2019; Accepted 08 December 2019 口.

Regular research paper: Published: 20 December 2019

Corresponding author's e-mail: mahmoud.hassan@soran.edu.iq

Copyright (C) 2019 Mahmoud A. Chawsheen, Hazem A. Al-Bustany.

This is an open-access article distributed under the Creative

Commons Attribution License. in response to growth factors and cytokines through cell surface receptors (Peso, et al., 1997; Laurino, et al., 2005; Dudu, et al., 2012). After activation, PI3Ks generate phosphatidylinositol-3,4,5-trisphosphate (PIP3) through the addition of a phosphate group to phosphatidylinositol4,5-bisphosphate (PIP2), and this process is an important step in initiating activation of their downstream targets (Whitman, et al., 1988; Auger, et al., 1989). Phosphatase and tensin homolog acts as a negative regulator of PI3K by dephosphorylating PIP3 to PIP2 (Chalhoub and Baker, 2009; Hollander, et al., 2011). Depending on the characteristics of their structure and specificity toward substrates, PI3Ks are classified into three groups: Class I PI3K, Class II PI3K, and Class III PI3K (Fruman, et al., 1998; Katso, et al., 2001). Class I, which we are mostly interested in, is subdivided into IA and IB. Class IA PI3Ks are heterodimers with the catalytic subunit p110 of one of the following isoforms: $\mathrm{p} 110 \alpha, \mathrm{p} 110 \beta$, or $\mathrm{p} 110 \delta$. These isoforms are encoded by the PIK3CA, PIK3CB, and PIK3CD genes, respectively (Engelman, et al., 2006; Katso, et al., 2001). PI3K Class IA members also have the regulatory subunit $\mathrm{p} 85$ of the $\mathrm{p} 85 \alpha$, $\mathrm{p} 55 \alpha, \mathrm{p} 50 \alpha, \mathrm{p} 85 \beta$, or $\mathrm{p} 85 \gamma$ isoform. The first three isoforms are encoded by PIK3R1 and are generated by differential splicing, and the last two isoforms are products of the PIK3R2 and PIK3R3 genes, respectively (Songyang, et al., 1993; Vanhaesebroeck, et al., 2001). Class IB PI3Ks are also heterodimers, but unlike Class IA, their catalytic subunit is the p110 $\gamma$ subunit integrated with regulatory isoforms p101 and $p 87$. The $p 110 \gamma$ subunit is encoded by the PIK3CG gene, and the p101 and p87 subunits are encoded by the PIK3R5 and PIK3R6 genes, respectively (Ueki, et al., 2002; Okkenhaug and Vanhaesebroeck, 2003; Amzel, et al., 2008). PIK3CA is frequently mutated in different types of cancer (Samuels and Waldman, 2010; Mangone, et al., 2012; Wang, et al., 2013; Schmidt, et al., 2018). Anomalies in p110 $\alpha$ are associated with increased enzymatic activity of PI3K and promote oncogenesis in affected cells (Bader, et al., 2005; Echeverria, et al., 2015). Due to their roles in promoting cancer cell survival, transformation, proliferation, and migration, PI3Ks are considered promising targets in cancer therapy (Vivanco and Sawyers, 2002; Hausler, et al., 1998; Vanhaesebroeck, et al., 2010). Since different PI3K 
isoforms have diverse capacities in cellular signaling and cancer progression, applying inhibitors that target individual isoforms may produce better therapeutic outcomes in treating cancer (Vanhaesebroeck, et al., 2010: Wang, et al., 2015). Many compounds have been introduced as PI3K $\alpha$ inhibitors, but not all of them have the same antitumor effects. It is convenient - especially for pre-clinical and clinical studies - to distinguish the most specific and potent chemical that delivers the highest inhibitory effect. Accordingly, in this study, we tried to uncover the best commercially available inhibitor(s) for targeting $\mathrm{PI} 3 \mathrm{~K} \alpha$ through predicting their specificity and potency using the docking software AutoDock Vina. This could help to improve treatment drugs in the future by cutting down the list of available ones to save more time, resources, and lives.

\section{Computational Methods}

\section{A. Preparation of Phosphoinositide 3-kinase and Inhibitors}

The crystal structure of $\mathrm{PI} 3 \mathrm{~K} \alpha$ was retrieved from the RCSB Protein Data Bank (PDB) with the code PDB-ID of 2RD0 (Gilliland, et al., 2000). There were four sections of missing residues in the $2 \mathrm{RD} 0$ crystal structure. Templates for the missing sections were adopted from the following PDBID entries: 3HHM, 3HIZ, 3ZIM, and 4JPS. All of the nonstandard amino acid residues were removed separately from these structures, and $\mathrm{PI} 3 \mathrm{~K} \alpha$ was prepared as the receptor and the inhibitors as ligands using Discovery Studio 4.1 (Dassault Systèmes, 2010). The overall PI3K model was built by the homology modeling module with Modeller 19.9 (Sali and Blundell, 1993). Molecular Graphics Laboratory (MGL) Tools 1.5.6 were used to prepare the protein structure for molecular docking. Polar hydrogens were added to the protein structure and saved in the "PDBQT" file format (MGLTools, 2017). In the present study, a total of 28 PI3K inhibitors were investigated (Table I). The inhibitors were selected based on their specificity for $\mathrm{PI} 3 \mathrm{~K} \alpha$ and were obtained from the suppliers Tocris Bioscience (www.tocris. com) and Sigma-Aldrich (www.sigmaaldrich.com). They can also be tracked using their unique compound identification number through the PubChem website (https://pubchem. ncbi.nlm.nih.gov) (Kim, et al., 2019). Some of the twodimensional (2D) structures were constructed by ChemDraw Pro 12.0 software and were saved in the "mol" file format (PerkinElmer, 2009). The 2D structures of the inhibitors were converted to three-dimensional structures using Discovery Studio 4.1. Finally, all of the structures were converted to the "PDBQT" file format with the Open Babel graphical user interface (O’Boyle, et al., 2011).

\section{B. AutoDock Vina}

The inhibitor docking site on PI3K $\alpha$ was defined by establishing a cube that covered the area of the docking stage. The established cube was mainly defined through the manipulation of a colored box at the $\mathrm{X}, \mathrm{Y}$, and $\mathrm{Z}$ axes. The volume of the cube can be as large or as small as required; however, there is an exponential increase in computation time as the volume of the box increases. For this study, we used the dimensions of $25 \AA \times 25 \AA \times 25 \AA$ to cover the inhibitor binding site with a grid point with $1.0 \AA$ spacing and center grid boxes of $60.127,62.455$, and 114.509 in the $\mathrm{X}, \mathrm{Y}$ and $\mathrm{Z}$ axes, respectively. Once the docking area was introduced, the coordinates of the grid box were written in a configuration file (a text document file) which fed into AutoDock Vina 1.1.2 software through a command line (Trott and Olson, 2010). The configuration file also specified the inhibitor (ligand) molecule and the PI3K (receptor) docking, and the broadness of the search can be set between 1 and 8 , where 8 is the most comprehensive search. AutoDock Vina was run on the Microsoft Windows 8.1 operating system with four central processing units $(1.7 \mathrm{GHz})$, and all PI3K $\alpha$ inhibitors were docked into the PI3K $\alpha$ (PDB-ID: 2RD0) protein (Trott and Olson, 2010). Three runs were performed for every single inhibitor.

\section{RESULTS}

To validate our methodology, the $\mathrm{PI} 3 \mathrm{~K} \alpha$ protein structure (receptor) (PDB-ID: 2RD0) was matched with the PI3K $\alpha$ isomers (ligands) (PDB-IDs: 3HHM, 3ZIM, 4FAD, and 4FA6)

TABLE I

LIST OF VERIFIED PI3K $\alpha$ INHIBITORS

\begin{tabular}{|c|c|c|c|c|c|}
\hline S. No. & PI3K $\alpha$ inhibitors & CID & S. No. & PI3K $\alpha$ inhibitors & CID \\
\hline 1. & KWT (3HHM) (Mandelker, et al., 2009) & 5288678 & 15 & LTURM 36 & 122705988 \\
\hline 2. & KKR (3ZIM) (Nacht, et al., 2013) & 70699406 & 16 & LY 294002 hydrochloride & 11957589 \\
\hline 3. & OTA (4FA6) (Le, et al., 2012) & 59258964 & 17 & LY 303511 & 3971 \\
\hline 5. & 3-Methyladenine & 135398661 & 19 & PF 05212384 & 44516953 \\
\hline 6. & A66 & 42636535 & 20 & PI 103 hydrochloride & 9884685 \\
\hline 7. & AS 252424 & 11630874 & 21 & PI 828 & 25181195 \\
\hline 10. & BAG 956 & 24882589 & 24 & Quercetin & 5280343 \\
\hline 11. & CZC 24832 & 42623951 & 25 & STK16-IN-1 & 58525066 \\
\hline 12. & ETP 45658 & 25229608 & 26 & TG 100713 & 17751063 \\
\hline 13. & GSK 1059615 & 23582824 & 27 & TGX 221 & 9907093 \\
\hline 14. & KU 0060648 & 11964036 & 28 & Wortmannin & 3003565 \\
\hline
\end{tabular}

CID: Compound identification number, PI3K: Phosphatidylinositol 3-kinase 
using the UCSF Chimera program version 1.10.1 (http://www. cgl.ucsf.edu/chimera/) (Pettersen, et al., 2004). The observed root-mean-square deviation values for these matchings were 0.904, 0.907, 1.174, and $1.174 \AA$, respectively (Fig. 1).

After successfully completing the docking protocol, the $\mathrm{PI} 3 \mathrm{~K} \alpha$ isomers described above were docked with the PI3K $\alpha$ protein. Our data showed that different energy requirements were needed to perform successful docking. In this regard, KKR was the least energy-demanding chemical, and 0TA was the highest energy-demanding chemical (Table II).

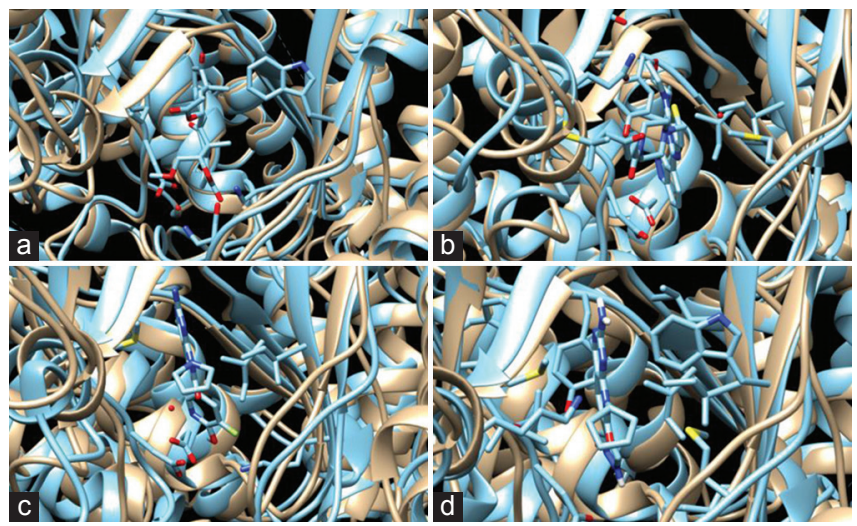

Fig. 1. (a-d) Superimposed structures of PI3K $\alpha$ proteins and their rootmean-square deviation (RMSD) values for their matchings with PI3K $\alpha$ protein. (a) 2RD0 (Gold) and 3HHM (Aqua) with RMSD: $0.904 \AA$; (b) 2RD0 (Gold) and 3ZIM (Aqua) with RMSD: $0.907 \AA$; (c) 2RD0 (Gold) and 4FAD (Aqua) with RMSD: $1.174 \AA$; (d) 2RD0 (Gold) and 4FA6 (Aqua) with RMSD: $1.174 \AA$.

TABLE II

Average Docking Scores of PI3K $\alpha$ Isomers (Ligands) Docked to PI3K $\alpha$ PRoteIN

\begin{tabular}{llcccc}
\hline \hline S. No. & PI3K $\alpha$ inhibitor & $1^{\text {st }}$ run & $2^{\text {nd }}$ run & $3^{\text {rd }}$ run & Av. \\
\hline 1. & KKR & -8.3 & -8.3 & -8.4 & -8.3 \\
2. & KWT & -7.3 & -7.3 & -7.3 & -7.3 \\
3. & OTB & -7.2 & -7.2 & -7.2 & -7.2 \\
4. & OTA & -6.4 & -6.4 & -6.4 & -6.4 \\
\hline \hline
\end{tabular}

PI3K $\alpha$ : Phosphatidylinositol 3-kinase $\alpha$
After that, each one of the remaining chemicals (24 inhibitors) was docked onto the PI3K $\alpha$ protein. Docking scores $(\mathrm{kcal} / \mathrm{mol})$ for the inhibitors and the average of three runs were sorted from lowest-energy poses (maximum docked energy in negative) to highest-energy poses (minimum docked energy in negative), as shown in Table III. Our data revealed that the studied inhibitors exhibited different affinities toward the targeted protein. PF 05212384 gave the highest docking score $(-9.2 \mathrm{kcal} / \mathrm{mol}), 3$-methyladenine gave the lowest docking score $(-4.8 \mathrm{kcal} / \mathrm{mol})$, and the others placed between these two values (Tables III).

\section{Discussion}

In this study, the type and potency of interactions between $\mathrm{PI} 3 \mathrm{~K} \alpha$ inhibitors and $\mathrm{PI} 3 \mathrm{~K} \alpha$ residues were predicted using the AutoDock Vina software. We used AutoDock Vina because it has been previously used in protein-ligand interactions and produced effective docking results (Perryman, et al., 2014: Jaghoori, et al., 2016). Inhibitors' orientation and their conformation were among the most important requirements to fulfill successful fitting between PI3K $\alpha$ binding sites and the studied inhibitors. In this regard, optimal interactions and best docking scores were considered criteria to understand the fittest conformation among those generated by AutoDock Vina for the studied inhibitors.

The results of docking PI3K $\alpha$ isomers with the PI3K $\alpha$ protein recognized KKR as the most potent inhibitor compared with others that are recognized as typical $\mathrm{PI} 3 \mathrm{~K} \alpha$ inhibitors (Table II). During the docking of KKR into the PI3Ka binding site (Fig. 2), the formation of hydrogen bonds with SER802, LYS830, and GLN887 and carbon-hydrogen interactions with SER801 was observed. Hydrophobic interactions were also detected between the inhibitor and PI $3 \mathrm{~K} \alpha$, causing alkyl interaction formation between protein residues MET800, MET886, VAL878, and MET950 and the inhibitor. The results obtained from the KKR-PI3Ka docking were used later on as a reference to choose the most potent and selective inhibitor(s) from the PI3K $\alpha$ inhibitors list (Table III). When PF 05212384 docked into the PI3Ka binding site (Fig. 3), it formed

TABLE III

Docking Scores (KCal/mol) for Chemicals Recommended as PI3K $\alpha$ Inhibitors. Data were obtained through AutoDock Vina 1.1.2 Software

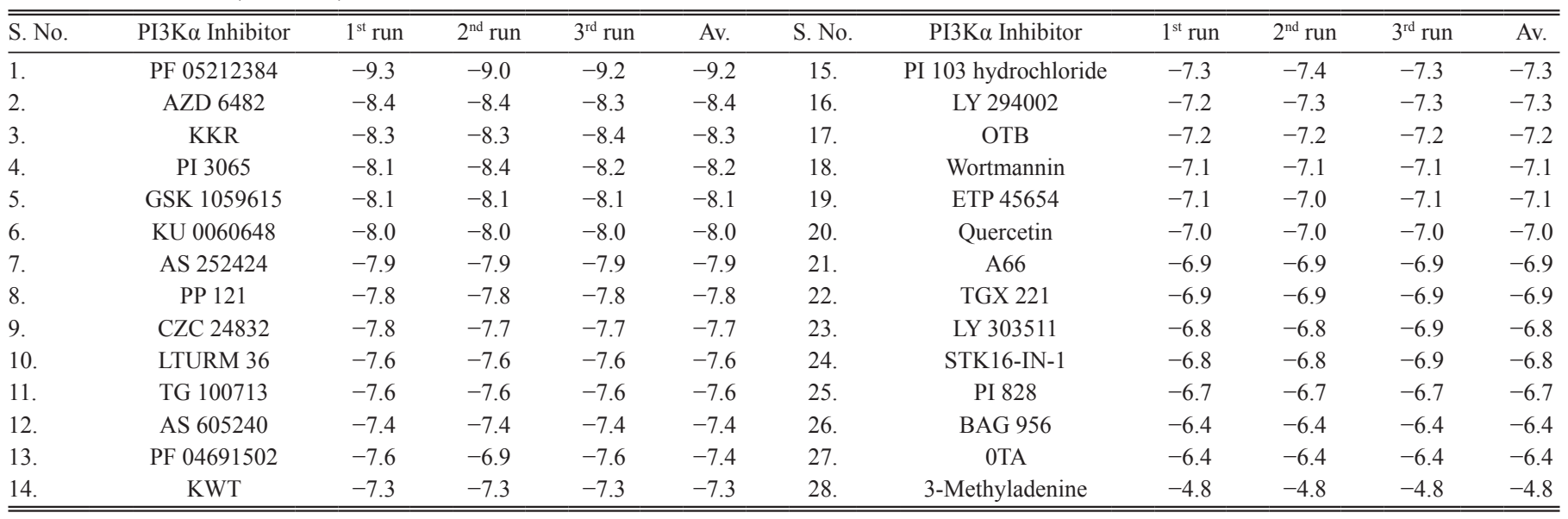

PI3K $\alpha$ : Phosphatidylinositol 3-kinase $\alpha$ 

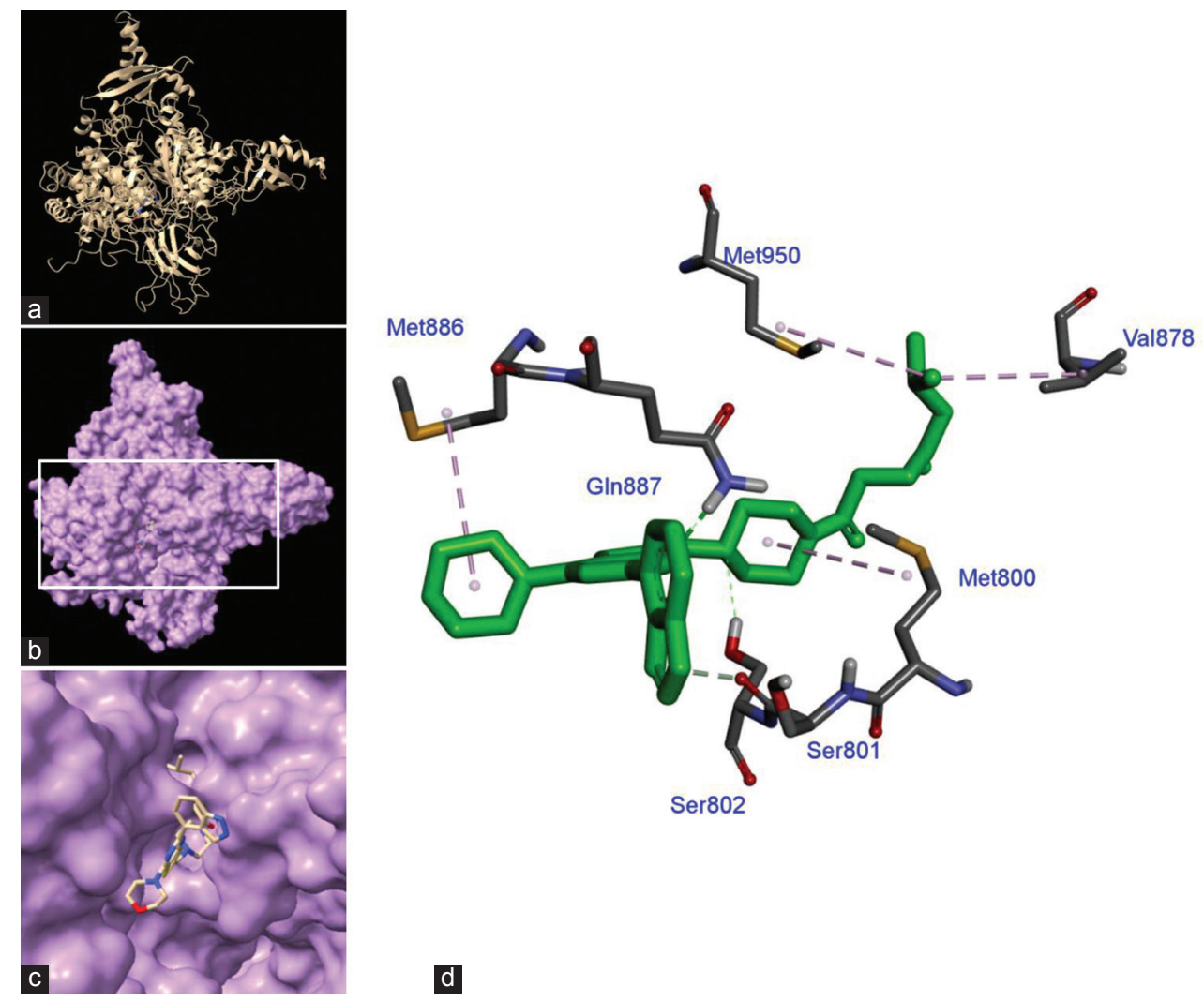

\section{d}

Fig. 2. KKR inhibitor docked to phosphatidylinositol 3-kinase $\alpha$ protein, (a) the protein as ribbons, (b and c) molecular surface and the inhibitor in active site, and (d) protein residues that interact with inhibitor.
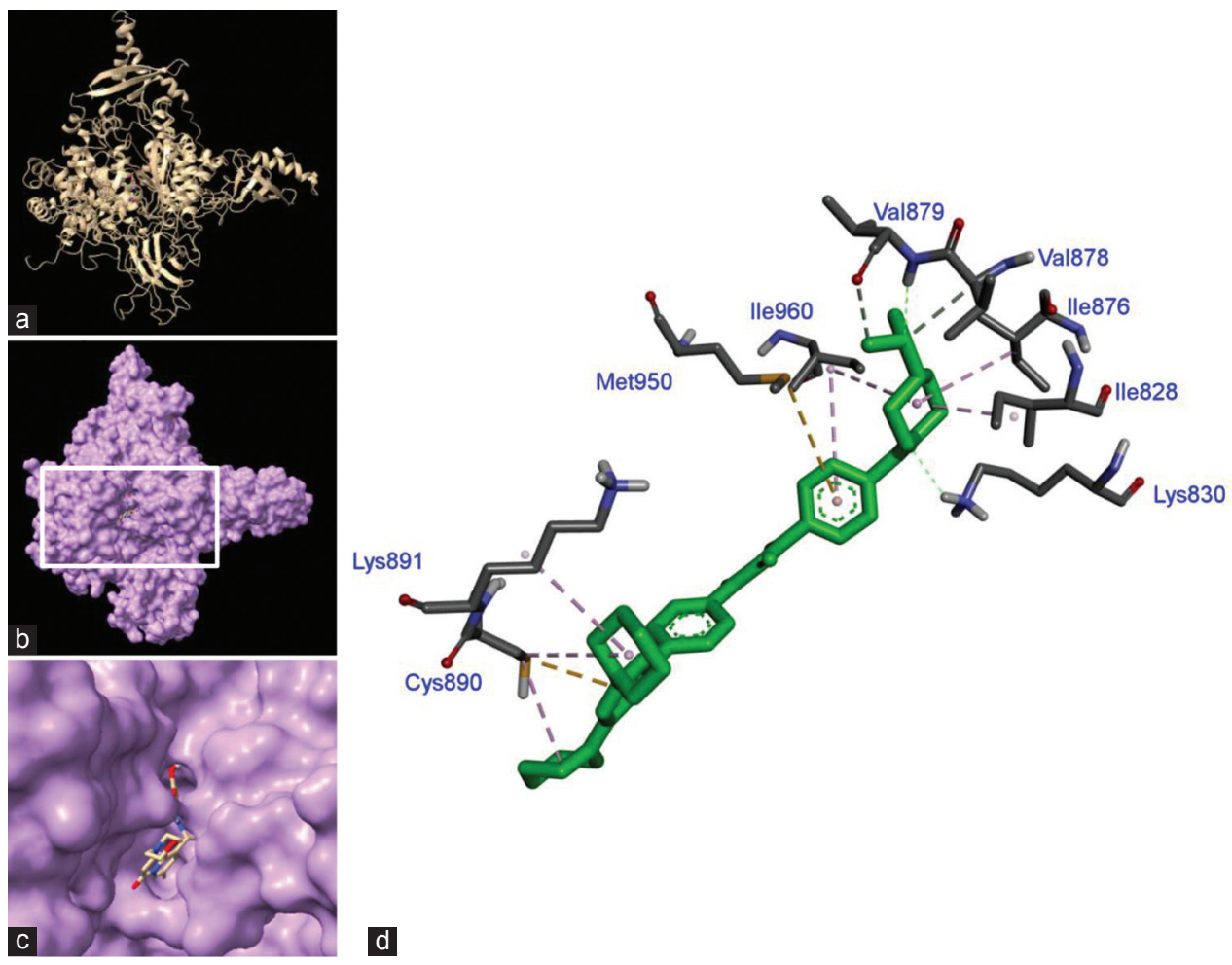

Fig. 3. Inhibitor PF 05212384 (19) docked with phosphatidylinositol 3-kinase $\alpha$ protein, (a) the protein as ribbons, (b and c) molecular surface and the inhibitor in active site, and (d) protein residues that interact with inhibitor.

hydrogen bonds with VAL879 and LYS830. Other nonbonded (pi-sulfur) interactions were formed between sulfur in CYS890 and MET950. Hydrophobic alkyl interactions were also observed between residues ILE828, ILE876, CYS890, LYS891, and ILE960 and the inhibitor. Moreover, a pi-alkyl interaction with ILE960 was also detected. 


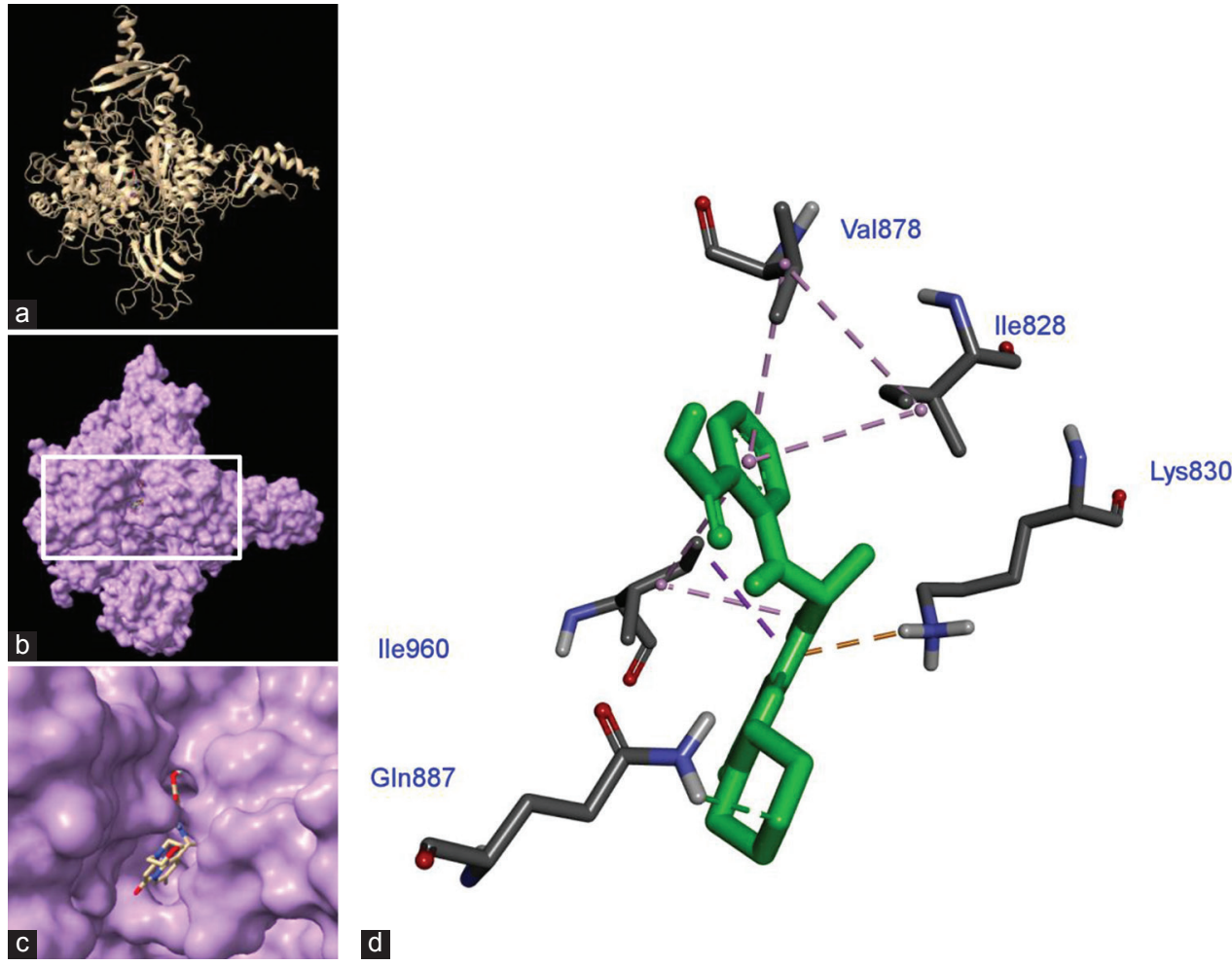

Fig. 4. Inhibitors AZD 6482 (9) docked to phosphatidylinositol 3-kinase $\alpha$ protein, (a) the protein as ribbons, (b and c) molecular surface and the inhibitor in active site, and (d) protein residues interacting residues with inhibitor.

Last but not the least, the inhibitor with the second lowestenergy pose was AZD 6482 (Fig. 4). This inhibitor formed hydrogen bonds with GLN887, an electrostatic interaction with LYS830, and hydrophobic interactions, including alkyl, pi-alkyl, and pi-sigma with ILE960 and pi-alkyl with ILE828 and VAL878.

Previously, other studies were carried out to predict the efficacy of PI3K inhibitors, but our results are not identical to theirs. This is more likely due to their use of different inhibitors and docking software (Sabbah, et al., 2010; Sabbah, et al., 2012; Singh and Bast, 2013; Kawade, et al., 2018).

\section{Conclusions}

Our analysis showed that among the studied PI3K $\alpha$ inhibitors, the PF 05212384 and AZD 6482 compounds are the best candidates for targeting PI3K $\alpha$. Interaction studies also confirm that these inhibitors interact with PI3K $\alpha$ by building hydrogen bonds with binding pocket residues in addition to hydrophobic interactions. In vitro and in vivo studies are needed to confirm our results in regard to the impact of candidate inhibitors on cancer cell survival and migration and their potential toxicity. It is also important to conduct molecular dynamic simulations to reach precise information regarding the dynamic behaviors and stability of the predicted complexes.

\section{REFERENCES}

Amzel, L.M., Huang, C.H., Mandelker, D., Lengauer, C., Gabelli, S.B. and Vogelstein, B., 2008. Structural comparisons of class I phosphoinositide 3-kinases. Nature Reviews Cancer, 8(9), pp.665-669.

Auger, K.R., Serunian, L.A., Soltoff, S.P., Libby, P. and Cantley, L.C., 1989. PDGF-dependent tyrosine phosphorylation stimulates production of novel polyphosphoinositides in intact cells. Cell, 57(1), pp.167-175.

Bader, A.G., Kang, S., Zhao, L. and Vogt, P.K., 2005. Oncogenic PI3K deregulates transcription and translation. Nature Reviews Cancer, 5(12), pp.921-929.

Chalhoub, N. and Baker, S.J., 2009. PTEN and the PI3-Kinase Pathway in Cancer. Annual Review of Pathology: Mechanisms of Disease, 4(1), pp.127-150.

Dassault Systèmes., 2016. Discovery Studio Modeling Environment (Version 4.1). Dassault Systèmes, San Diego.

Dudu, V., Able, R.A. Jr., Rotari, V., Kong, Q. and Vazquez, M., 2012. Role of epidermal growth factor-triggered PI3K/Akt signaling in the migration of medulloblastoma-derived cells. Cellular and Molecular Bioengineering, 5(4), pp.502-413.

Echeverria, I., Liu, Y., Gabelli, S. B. and Amzel, L.M., 2015. Oncogenic mutations weaken the interactions that stabilize the p110alpha-p85alpha heterodimer in phosphatidylinositol 3-kinase alpha. FEBS J, 282(18), pp.3528-3542.

Engelman, J.A., Luo, J. and Cantley, L.C., 2006. The evolution of phosphatidylinositol 3-kinases as regulators of growth and metabolism. Nature Reviews Genetics, 7, p.606.

Fruman, D.A., Meyers, R.E. and Cantley, L.C., 1998. Phosphoinositide kinases. Annual Review of Biochemistry, 67, pp.481-507.

Gilliland, G., Berman, H.M., Weissig, H., Shindyalov, I.N., Westbrook, J., Bourne, P.E. and Feng, Z., 2000. The protein data bank. Nucleic Acids Res, 28(1), pp.235-242.

Hancock, J.T., 2010. Cell Signalling. $3^{\text {rd }}$ ed. Oxford University Press, Oxford, New York.

Hausler, P., Papoff, G., Eramo, A., Reif, K., Cantrell, D.A. and Ruberti, G., 1998. Protection of CD95-mediated apoptosis by activation of phosphatidylinositide 3-kinase and protein kinase B. European Journal of Immunology, 28(1), pp.57-69. 
Hollander, M.C., Blumenthal, G.M. and Dennis, P.A., 2011. PTEN loss in the continuum of common cancers, rare syndromes and mouse models. Nature Reviews Cancer, 11(4), pp.289-301.

Jaghoori, M.M., Bleijlevens, B. and Olabarriaga, S.D., 2016. 1001 Ways to run autodock vina for virtual screening. Journal of Computer-Aided Molecular Design, 30(3), pp.237-249.

Katso, R., Okkenhaug, K., Ahmadi, K., White, S., Timms, J. and Waterfield, M.D., 2001. Cellular function of phosphoinositide 3-kinases: Implications for development, homeostasis, and cancer. Annual Review of Cell and Developmental Biology, 17, pp.615-675.

Kawade, V.S., Satpute, P.S., Dhulap, S.A. and Gurjar, S., 2018. Therapeutic potential of PI3K/Akt/mTOR signalling pathway: Effective combination therapy for cancer. Indian Journal of Pharmaceutical Sciences, 80(4), pp.

Kim, S., Chen, J., Cheng, T., Gindulyte, A., He, J., He, S. and Bolton, E.E., 2019. PubChem 2019 update: Improved access to chemical data. Nucleic Acids Res, 47(D1), pp.D1102-D1109.

Laurino, L., Wang, X.X., de la Houssaye, B.A., Sosa, L., Dupraz, S., Cáceres, A., Quiroga, S., 2005. PI3K activation by IGF-1 is essential for the regulation of membrane expansion at the nerve growth cone. Journal of Cell Science, 118(16), pp.3653-3662.

Le, P.T., Cheng, H., Ninkovic, S., Plewe, M., Huang, X., Wang, H. and Zhang, E., 2012. Design and synthesis of a novel pyrrolidinyl pyrido pyrimidinone derivative as a potent inhibitor of PI3Kalpha and mTOR. Bioorganic and Medicinal Chemistry Letters, 22(15), pp.5098-5103.

Liu, P., Cheng, H., Roberts, T.M. and Zhao, J.J., 2009. Targeting the phosphoinositide 3-kinase pathway in cancer. Nature Reviews Drug Discovery, 8(8), pp.627-644.

Luo, J., Manning, B.D. and Cantley, L.C., 2003. Targeting the PI3K-Akt pathway in human cancer: Rationale and promise. Cancer Cell, 4(4), pp.257-262.

Mandelker, D., Gabelli, S.B., Schmidt-Kittler, O., Zhu, J., Cheong, I., Huang, C.H. and Amzel, L.M., 2009. A frequent kinase domain mutation that changes the interaction between PI3Kalpha and the membrane. Proceedings of the National Academy of Sciences of the United States of America, 106(40), pp.16996-17001.

Mangone, F.R., Bobrovnitchaia, I.G., Salaorni, S., Manuli, E. and Nagai, M.A., 2012. PIK3CA exon 20 mutations are associated with poor prognosis in breast cancer patients. Clinics, 67(11), pp.1285-1290.

MGLTools., 2017. Molecular Graphics Laboratory Tools. Available from: http:// www.mgltools.scripps.edu. [Last accessed on 2017 Aug 01].

Nacht, M., Qiao, L., Sheets, M.P., St Martin, T., Labenski, M., Mazdiyasni, H. and Singh, J., 2013. Discovery of a potent and isoform-selective targeted covalent inhibitor of the lipid kinase PI3Kalpha. Journal of Medicinal Chemistry, 56(3), pp.712-721.

O’Boyle, N.M., Banck, M., James, C.A., Morley, C., Vandermeersch, T. and Hutchison, G.R., 2011. Open Babel: An open chemical toolbox. Journal of Cheminformatics, 3(1), p.33.

Okkenhaug, K. and Vanhaesebroeck, B., 2003. PI3K in lymphocyte development, differentiation and activation. Nature Reviews Immunology, 3, p.317.

PerkinElmer., 2009. ChemDraw Professional. Available from: http:// www.cambridgesoft.com/Ensemble_for_Chemistry/ChemDraw/ ChemDrawProfessional/Default.aspx. [Last accessed on 2017 Jul 01].

Perryman, A.L., Santiago, D.N., Forli, S., Santos-Martins, D. and Olson, A.J., 2014. Virtual screening with autodock vina and the common pharmacophore engine of a low diversity library of fragments and hits against the three allosteric sites of HIV integrase: Participation in the SAMPL4 protein ligand binding challenge. Journal of Computer-Aided Molecular Design, 28(4), pp.429-441.

Peso, L.D., González-García, M., Page, C., Herrera, R. and Nuñez, G., 1997. Interleukin-3-induced phosphorylation of $\mathrm{BAD}$ through the protein kinase akt. Science, 278(5338), pp.687-689.

Pettersen, E.F., Goddard, T.D., Huang, C.C., Couch, G.S., Greenblatt, D.M., Meng, E.C. and Ferrin, T.E., 2004. UCSF Chimera--a visualization system for exploratory research and analysis. Journal of Computational Chemistry, 25(13), pp.1605-1612.

Sabbah, D.A., Simms, N.A., Brattain, M.G., Vennerstrom, J.L. and Zhong, H., 2012. Biological evaluation and docking studies of recently identified inhibitors of phosphoinositide-3-kinases. Bioorganic and Medicinal Chemistry Letters, 22(2), pp.876-880.

Sabbah, D.A., Vennerstrom, J.L. and Zhong, H., 2010. Docking studies on isoform-specific inhibition of phosphoinositide-3-kinases. Journal of Chemical Information and Modeling, 50(10), pp.1887-1898.

Sali, A. and Blundell, T.L., 1993. Comparative protein modelling by satisfaction of spatial restraints. Journal of Molecular Biology, 234(3), pp.779-815.

Samuels, Y. and Waldman, T., 2010. Oncogenic mutations of PIK3CA in human cancers. Current Topics in Microbiology and Immunology, 347, pp.21-41.

Schmidt, H., Kulasinghe, A., Allcock, R.J.N., Tan, L.Y., Mokany, E., Kenny, L. and Punyadeera, C., 2018. A Pilot study to non-invasively track PIK3CA mutation in head and neck cancer. Diagnostics, 8(4), p.79.

Singh, P. and Bast, F., 2013. Multitargeted molecular docking study of plantderived natural products on phosphoinositide-3 kinase pathway components. Medicinal Chemistry Research, 23(4), pp.1690-1700.

Songyang, Z., Shoelson, S.E., Chaudhuri, M., Gish, G., Pawson, T., Haser, W.G., King, F., Roberts, T., Ratnofsky, S. and Lechleider, R.J., 1993. SH2 domains recognize specific phosphopeptide sequences. Cell, 72(5), pp.767-778.

Trott, O. and Olson, A.J., 2010. Autodock vina: Improving the speed and accuracy of docking with a new scoring function, efficient optimization, and multithreading. Journal of Computational Chemistry, 31(2), pp.455-461.

Ueki, K., Fruman, D.A., Brachmann, S.M., Tseng, Y.H., Cantley, L.C. and Kahn, C.R., 2002. Molecular balance between the regulatory and catalytic subunits of phosphoinositide 3-kinase regulates cell signaling and survival. Molecular and Cellular Biology, 22(3), p.965.

Vanhaesebroeck, B., Leevers, S.J., Ahmadi, K., Timms, J., Katso, R., Driscoll, P.C. and Waterfield, M.D., 2001. Synthesis and function of 3-phosphorylated inositol lipids. Annual Review of Biochemistry, 70, pp.535-602.

Vanhaesebroeck, B., Vogt, P.K. and Rommel, C., 2010. PI3K: From the bench to the clinic and back. Current Topics in Microbiology and Immunology, 347, pp.1-19.

Vivanco, I. and Sawyers, C.L., 2002. The phosphatidylinositol 3-kinase AKT pathway in human cancer. Nature Reviews Cancer, 2(7), pp.489-501.

Wang, W.F., Xie, Y., Zhou, Z.H., Qin, Z.H., Wu, J.C. and He, J.K., 2013. PIK3CA hypomethylation plays a key role in activation of the PI3K/AKT pathway in esophageal cancer in Chinese patients. Acta Pharmacologica Sinica, 34(12), pp.1560-1567.

Wang, X., Ding, J. and Meng, L.H., 2015. PI3K isoform-selective inhibitors: Next-generation targeted cancer therapies. Acta Pharmacologica Sinica, 36(10), pp.1170-1176.

Whitman, M., Downes, C.P., Keeler, M., Keller, T. and Cantley, L., 1988. Type I phosphatidylinositol kinase makes a novel inositol phospholipid, phosphatidylinositol-3-phosphate. Nature, 332(6165), pp.644-646. 